\title{
Human mesenchymal stromal cells from adipose tissue of the neck
}

\author{
Florian Böhrnsen · Nicole Rotter · Ulrich Lindner • \\ Markus Meier • Barbara Wollenberg • \\ Jürgen Rohwedel · Jan Kramer
}

Received: 19 November 2011 / Accepted: 19 January 2012 / Published online: 5 February 2012

(C) The Author(s) 2012. This article is published with open access at Springerlink.com

\begin{abstract}
Mesenchymal stromal cells (MSC) have been introduced into the field of tissue-engineered airway transplantation. Since patients with extensive tracheal defects often require an open tracheotomy, this study investigated if MSC could be obtained from the adipose tissue of the neck during this procedure. Cells were isolated by plastic adherence from the adipose tissue of 8 patients. Cell isolates were analyzed for (i) proliferation, (ii) the expression of CD marker molecules and (iii) multilineage differentiation. The isolated spindle-shaped cells showed a high proliferation capacity and the flow cytometric analysis revealed a distinct population meeting the criteria for MSC. Using classical MSC cultivation protocols the characterized cells showed adipogenic, chondrogenic and osteogenic differentiation for all analyzed cell isolates. This study was able to demonstrate that sufficient amounts of stem/progenitor cells can be easily isolated from adipose tissue of the
\end{abstract}

F. Böhrnsen · J. Rohwedel · J. Kramer

Institute of Virology and Cell Biology, University of Lübeck,

Lübeck, Germany

F. Böhrnsen · U. Lindner · M. Meier · J. Kramer

Medical Department I, University of Lübeck, Lübeck, Germany

Present Address:

F. Böhrnsen ( $\square)$

Department of Oral and Maxillofacial Surgery,

George-Augusta-University, Robert-Koch-Str. 40,

37075 Göttingen, Germany

e-mail: b.f.boehrnsen@googlemail.com

N. Rotter

Department of Otolaryngology, Ulm University, Ulm, Germany

B. Wollenberg

Department of Otolaryngology, University of Lübeck,

Lübeck, Germany neck obtained during open tracheotomy. These cells may be a source for future tracheal replacement therapies.

Keywords Mesenchymal stem cells $\cdot$ Mesenchymal stromal cells $\cdot$ MSC $\cdot$ Tissue engineering $\cdot$ Tracheal transplantation $\cdot$ Adipose tissue $\cdot$ Tracheotomy

\section{Introduction}

Airway stenosis can lead to atelectasis and severe obstructive pneumonia. To secure airway function tracheotomy is often necessary. Moreover, tracheomalacia due to trauma, severe inflammation or malignant diseases may require extensive surgical treatment. Various therapeutic approaches for stenosis and obstruction of the trachea or bronchi have been reported, including bronchoscopic dilatation, laser ablation, airway stenting and surgical bronchoplasty [1, 2]. The current gold standard in surgical treatment of severe stenosis or defects is resection with end-to-end anastomosis. However, large airway defects $(>5 \mathrm{~cm})$ still present a major problem for clinicians because of the absence of effective methods of treatment. Recent studies have focused on the replacement of the cervical trachea or main bronchi based on the concept of in situ-tissue engineering [3, 4]. Attempts to provide synthetic grafts for application in humans have been associated with poor epithelization, exposure of the prosthesis matrix and poor functional outcome [5, 6]. Allograft transplants such as aorta, functioning as a biologic incubator, may allow host cells to migrate into the airway transplant in vivo [7]. In particular, after malignant or infectious diseases lifelong immunosuppressive medication is contraindicated, but it is necessary to avoid rejection of allogenic material. This restricts the clinical application of allografts. Therefore, 
autologous transplants are favored for replacement strategies. Autologous bone marrow mesenchymal stem cells have recently been introduced into the field of tissueengineered airway transplantation. Besides autologous epithelial cells and chondrocytes, bone marrow-derived mesenchymal stem cells were used for the complete replacement of the left bronchus in a bioengineered human trachea [8]. Bone marrow mesenchymal stem cells have been found to differentiate along multiple mesenchymal lineages [9-11]. Even though it is commonly accepted that multipotent mesenchymal stem cells exist, there is clear evidence that isolation via plastic adherence results in heterogeneous populations including subsets of stem/progenitor cells with a contingently different stem cell potential. To point out this heterogeneity multipotent fibroblast colonyforming cells have been reclassified as mesenchymal stromal cells (MSC) [11]. Besides bone marrow, other sources of adult stem cells have been characterized, posting the hypothesis that stem cells capable of multilineage differentiation might reside in any post natal-organ [12]. Adiposederived MSC possess a particular relevance for tissue engineering settings because these cells can be harvested and handled easily and effectively without donor site morbidity. In rats regeneration of the trachea using a bioengineered scaffold with adipose-derived MSC has already been reported [13].

This study investigated whether adult MSC can be retrieved during a tracheotomy from the adipose tissue of the neck. The cells were isolated from the adipose biopsies and characterized by their adherence to plastic culture dishes, their fibroblastoid morphology, their ability to proliferate in culture and by means of flow cytometric analysis. The stem/progenitor cell isolates showed characteristics of multipotent adult stem cells, and given the appropriate culture conditions, demonstrated multilineage differentiation into adipogenic, osteogenic and chondrogenic cells. Furthermore, there is strong evidence that these adipose tissuederived cells meet the requirements for MSC [11] and may therefore be applicable for clinical tissue-engineered airway transplantation in the future.

\section{Materials and methods}

Isolation of human stem/progenitor cells

The isolation of human stem/progenitor cells from the adipose tissue surrounding the trachea was carried out with samples of eight patients, aged between 55 and 78 years, in accordance with the patients 'informed consent (approval by the ethics committee, University of Lübeck, no. 05-218) and given indication for surgical tracheotomy. The biopsy was removed during the classic procedure of an open tracheotomy which was performed under general anesthesia in the operating room of the intensive care unit. Approximately $2-3 \mathrm{~g}$ of adipose tissue were removed from the neck as a routine procedure and immediately transferred to the laboratory for further processing. Adipose tissue samples were digested with basal medium supplemented with $1 \mathrm{mg} / \mathrm{ml}$ collagenase A (Sigma, München, Germany) for $45 \mathrm{~min}$ at $37^{\circ} \mathrm{C}$, sieved, centrifuged, and washed with basal medium. The number of cells was determined and the cell suspension was plated onto $75 \mathrm{~cm}^{2}$ tissue culture flasks (TPP, Trasadingen, Switzerland). The number of cells obtained directly after isolation was around $4 \times 10^{5}$ cells. Non adherent cells were removed by the first medium change after 2 days. Single colonies of adherent fibroblastlike cells were first visible after $72 \mathrm{~h}$ of cultivation. All cultivations were performed at $37^{\circ} \mathrm{C}$ and $5 \% \mathrm{CO}_{2}$.

\section{Cultivation of human stem/progenitor cells}

Stem/progenitor cells were cultured in basal medium consisting of Dulbecco's modified Eagle's medium (DMEM, Invitrogen, Paisley, U.K.) supplemented with $1 \%$ sodium pyruvate (PAA, Pasching, Austria), 1\% L-glutamine (PAA, Pasching, Austria), 1\% MEM non-essential amino acids (Invitrogen, Paisley, U.K.), 1\% penicillin/streptomycin (PAA, Pasching, Austria) and 10\% fetal bovine serum (PAA, Pasching, Austria). When adherent cells reached approximately $80-90 \%$ confluence, they were washed with phosphate-buffered saline (PBS), trypsinized and centrifuged for $5 \mathrm{~min}$ at $250 \mathrm{~g}$. The cells were plated at a density of $1 \times 10^{4}$ cells $/ \mathrm{cm}^{2}$ and passaged every $4-10$ days. When reaching subconfluence, the cells were phenotyped using flow cytometric analysis (passage p4) or replated for differentiation. Passages used for differentiation in three independent samples per experimental group $(n=3)$ were $\mathrm{p} 4$, p6 and $\mathrm{p} 8$ in all stem/progenitor cell isolates. The daily doubling index was used to determine the proliferation and growth properties of the human stem/progenitor cells.

Flowcytometric analysis of human stem/progenitor cells

Trypsin/EDTA-(0.25\%) treated cells (4th passage) were washed twice with FACS buffer (PBS, $1 \%$ BSA and $0.1 \%$ $\mathrm{NaN}_{3}$ ), adjusted to approximately $5 \times 10^{5}$ cells $/ \mathrm{ml}$ and subsequently stained. A $100-\mu 1$ cell suspension was incubated with either $10 \mu$ phycoerythrin (PE)-conjugated monoclonal antibodies (mAbs) or $10 \mu \mathrm{l}$ non-conjugated mAbs and a secondary goat anti-mouse IgG1-PE at $4^{\circ} \mathrm{C}$ for $30 \mathrm{~min}$. To discriminate human stem/progenitor cells from cells of hematopoietic origin, isolates were stained for CD34 and CD45. In addition, the following antigens were included into the phenotyping profile: CD29, CD44, CD54, CD73, CD105, CD106, CD140b and CD166. Prior to the flow 
cytometric analysis, all samples were filled up to a total volume of $500 \mu \mathrm{l}$ with FACS buffer. Cells were analyzed on a Cytomics FC 500 flow cytometer using cytomics CXP software (Beckman Coulter, Krefeld, Germany). At least 10,000 events were acquired and analyzed using a oneparametric protocol (FL2) and FSC/SSC dot plot diagram to exclude cell debris by gating. Non-specific isotypematched controls were used to determine background fluorescence. All mAbs against the human antigens CD34, CD45, CD29, CD44, CD54, CD73, CD105, CD106, CD140b and CD166 were purchased from Becton-Dickinson (Heidelberg, Germany).

\section{Differentiation of human stem/progenitor cells}

All differentiation assays have been carried out with three independent samples per experimental group $(n=3)$. Chondrogenic differentiation was performed using micro mass body (MMB) cultivation [14]. Cells were trypsinized, counted and basal medium was replaced by chondrogenic induction medium. Aliquots of $2 \times 10^{5}$ cells in $0.5 \mathrm{ml}$ chondrogenic induction medium were centrifuged at $65 \mathrm{~g}$ in $15 \mathrm{ml}$ polypropylene conical tubes. Chondrogenic induction medium consisted of basal medium supplemented with $0.1 \mu \mathrm{M}$ dexamethasone (Merk, Darmstadt, Germany), $300 \mu \mathrm{M}$ ascorbic acid (Sigma, München, Germany), $1 \mathrm{mM}$ L-proline (Sigma, München, Germany), $10 \mathrm{ng} / \mathrm{ml}$ transforming growth factor (TGF) $\beta_{3}$, (R\&D, Wiesbaden, Germany) and $1 \%$ ITS premix (Becton-Dickinson, Heidelberg, Germany: $6.25 \mu \mathrm{g} / \mathrm{ml}$ insulin; $6.25 \mu \mathrm{g} / \mathrm{ml}$ transferrin; $6.25 \mu \mathrm{g} / \mathrm{ml}$ selenious acid; $1.25 \mathrm{mg} / \mathrm{ml}$ bovine serum albumin; $5.35 \mathrm{mg} / \mathrm{ml}$ linoleic acid). Samples of MMBs were taken for RNA-isolation (4 MMB per experimental time point per sample per day), histochemical or immunhistochemical analysis (1 MMB per sample per day) during the course of chondrogenic differentiation. MMBs prepared for histochemical and immunhisto-chemical staining were embedded in Tissue-Tek O.C.T. (Sakura Finetechnical, Tokyo, Japan), frozen at $-80^{\circ} \mathrm{C}$ and cryosectioned $(10 \mu \mathrm{m})$ for further analysis. To screen for proteoglycan deposits or marker protein expression within the chondrogenic MMBs, cryosections were fixed and stained with Alcian blue or immunostained. Uninduced MMBs were stained as negative controls.

To analyze adipogenic and osteogenic differentiation, isolated stem/progenitor cells were differentiated via monolayer protocols $[10,15]$. Adipogenic and osteogenic induction of the stem/progenitor cells was performed at $80-90 \%$ confluence. To induce osteogenic differentiation cells were treated with osteogenic medium for 25 days. Osteogenic medium consisted of basal medium supplemented with $0.1 \mu \mathrm{M}$ dexamethasone (Merk, Darmstadt, Germany), $10 \mathrm{mM} \beta$-glycerolphosphate (Sigma, München, Germany) and $300 \mu \mathrm{M}$ ascorbic acid (Sigma, München, Germany). To induce adipogenic differentiation cells were treated with adipogenic induction medium and adipogenic maintenance medium for 25 days. Induction medium consisted of basal medium supplemented with $0.5 \mathrm{mM}$ 3-isobutyl-1-methylxanthine (IBMX Sigma, München, Germany), $1 \mu \mathrm{M}$ dexamethasone (Merk, Darmstadt, Germany), $200 \mu \mathrm{M}$ indomethacin (Sigma, München, Germany) and $2 \mu \mathrm{M}$ insulin (Sigma, München, Germany). Following a four-day induction period, the adipogenic induction medium was replaced with adipogenic maintenance medium consisting of basal medium supplemented with $2 \mu \mathrm{M}$ insulin for 3 days. This cycle was repeated three times and ultimately followed by a four-day period of adipogenic maintenance culture.

Lipid accumulation during adipogenic differentiation was demonstrated by Sudan III staining. Cells were washed with PBS followed by staining with a $0.2 \%$ solution of Sudan III (Sigma, München, Germany) in $70 \%$ ethanol. Alkaline Phosphatase (AP) activity of stem/progenitor cells differentiating along the osteogenic lineage was demonstrated using the AP staining kit (Sigma, München, Germany).

Quantitative analysis of histochemical staining

To analyze the differentiation of human adipose tissuederived stem/progenitor cells from the neck by AP or Sudan III staining, ten areas of $0.77 \mathrm{~mm}^{2}$ for osteogenic differentiation and ten areas of $0.235 \mathrm{~mm}^{2}$ for adipogenic differentiation were quantified per sample per day. The stained areas were measured in relation to the total area of cells using ImageJ software (NIH, Bethesda, MD, USA) and quantified in percent. Chondrogenic differentiation was analyzed by measuring Alcian blue-positive stained areas in relation to the total area of the sectioned MMB using ImageJ software (NIH, Bethesda, MD, USA) and quantified in percent.

\section{Fluorescent immunostaining}

Human stem/progenitor cells cultured on chamber slides or MMB cryosections were rinsed three times with PBS, fixed for 5 min with pre-cooled $\left(-20^{\circ} \mathrm{C}\right)$ methanol-acetone at $4^{\circ} \mathrm{C}$, washed four times with PBS and incubated at room temperature for $30 \mathrm{~min}$ with $7.5 \%$ bovine serum albumin. Specimens were then incubated for $1 \mathrm{~h}$ with a primary antibody in a humidified chamber at $37^{\circ} \mathrm{C}$. Antibodies specific for the following proteins were used (designation, dilution ratio in PBS as well as references are given in parentheses): stromal cell surface marker (STRO-1; 1:50; [16]), collagen type II (II-II-6B3; 1:20; [17]), collagen type X (XAC9; $1: 20 ;[18]$ ), osteopontin (MPIIIB101; 1:20; [19]), bone 
sialoprotein I + II (WVID1(9C5); 1:20; [19]). The antibodies were obtained from the Developmental Studies Hybridoma Bank (University of Iowa, Iowa City, IA, USA). After rinsing four times with PBS, slides were incubated for $1 \mathrm{~h}$ at $37^{\circ} \mathrm{C}$ with either fluorescein isothiocyanate (FITC, Dianova, Hamburg, Germany; 1:200) or cyanine3 (Cy3, Dianova, Hamburg, Germany; 1:600) labeled anti-mouse IgG as well as 4',6-Diamidino-2-phenylindole dihydrochloride (DAPI; Sigma, Taufkirchen, Germany). Slides were washed four times in PBS and briefly washed in distilled water. After immunostaining the specimens were embedded in Vectashield mounting medium (Vector, Burlingame, CA, USA) and analyzed with the fluorescence microscope Axioskop (ZEISS, Oberkochen, Germany). Negative controls were performed using the secondary antibody only.

\section{RT-PCR analysis}

Stem/progenitor cells differentiated via monolayer or MMB were collected at different time points, washed twice with PBS and total RNA was isolated using a standardized RNA Isolation Kit (Macherey \& Nagel, Düren, Germany). The RNA concentrations were determined by measuring the absorbance at 260 and $280 \mathrm{~nm}$. Samples of $500 \mathrm{ng}$ RNA were reverse transcribed using oligo-dT primer and Superscript II reverse transcriptase following the manufacturer's recommendations (Invitrogen, Paisley, U.K.). Aliquots of $1 \mu \mathrm{l}$ from the reverse transcriptase reactions were used for amplification of transcripts using primers specific for the analyzed genes and Taq polymerase according to the manufacturer's instructions (Fermentas, St. Leon, Germany). Reverse transcriptase reactions were denatured for $2 \mathrm{~min}$ at $95^{\circ} \mathrm{C}$, followed by amplification for 30-40 cycles of $40 \mathrm{~s}$ denaturation at $95^{\circ} \mathrm{C}, 40 \mathrm{~s}$ annealing at the primer-specific temperature and $50 \mathrm{~s}$ elongation at $72^{\circ} \mathrm{C}$. Primers specific for the following genes were used (sequence, annealing temperature as well as size are given in parentheses): PPAR $\gamma\left(5^{\prime}\right.$ - AAA CTC TGG GAG ATT CTC CT - $3^{\prime}, 5^{\prime}$ - TCT TGT GAA TGG AAT GTC TT $-3^{\prime}, 56^{\circ} \mathrm{C}, 247$ bp) [20], aP2 (5'- GCT TTG CCA CCA GGA AAG TG -3', 5'- ATG ACG CAT TCC ACC ACC AG -3', 60 ${ }^{\circ} \mathrm{C}, 279$ bp) [20], C/EBPalpha (5'- AGA AAG GGG TGG AAA CAT AGG -3', 5'- GAA AGC TGA GGG CAA AGG $-3^{\prime}, 58^{\circ} \mathrm{C}, 685 \mathrm{bp}$ ) [20], osteopontin (5'- ACT GAT TTT CCC ACG GAC CT -3', 5'- CAT TCA ACT CCT CGC TTT CC $-3^{\prime}, 58^{\circ} \mathrm{C}, 199 \mathrm{bp}$ ), osteocalcin (5' - CTC ACA CTC CTC GCC CTA TT - $3^{\prime}, 5^{\prime}$ - CGC CTG GGT CTC TTC ACT AC $-3^{\prime}, 58^{\circ} \mathrm{C}, 143 \mathrm{bp}$ ), collagen type II (5'- AGG CTC CCA GAA CAT CAC CT $-3^{\prime}$, 5'- ACA GTC TTG CCC CAC TTA CC $-3^{\prime} \quad 55^{\circ} \mathrm{C}$, 472 bp) [21], Aggrecan (5'- GCA GAG ACG CAT CTA GAA ATT G - $3^{\prime}, 5^{\prime}$ - GGT AAT TGC AGG GAA CAT CAT T $\left.-3^{\prime}, 55^{\circ} \mathrm{C}, 504 \mathrm{bp}\right)$ [21] and GAPDH (5' - CCG CAT CTT CTT TTG CGT CGC -3', 5' - GCA ACT GTG AGG
AGG GGA GAT TCA G - $\left.3^{\prime}, 55^{\circ} \mathrm{C}, 1100 \mathrm{bp}\right)$. Electrophoretic separation of PCR products was carried out on $2 \%$ agarose gels $[2 \%(\mathrm{w} / \mathrm{v})$ agarose (Roth, Karlsruhe, Germany)], $0.7 \mathrm{ng} / \mathrm{ml}$ ethidium bromide (Roth, Karlsruhe, Germany). The fragments were analyzed by computer-assisted densitometry in relation to GAPDH gene expression. The densitometric values of each marker were calculated in relation to GAPDH. From these values the highest of each marker was taken as $100 \%$. Distilled water and no-RT reactions were always included as a negative control.

Statistical analysis

Statistical analysis was performed using SigmaPlot 2000 software (Systat, Erkrath, Germany) and calculated according to the student's $t$ test. Samples were analyzed at least in three independent experiments $(n=3)$.

\section{Results}

Successful establishment of stem/progenitor cells after tracheotomy

During an open tracheotomy stem/progenitor cells were isolated from subcutaneous adipose tissue of eight patients, aged between 55 and 78 years. Plastic adherent cell populations from adipose tissue of the neck exhibited a typical spindleshaped morphology (Fig. 1a). The first colonies of fibroblastlike cells could be observed after $72 \mathrm{~h}$, with a $100 \%$ successful rate of stem/progenitor cell isolation. All cell isolates displayed stable growth characteristics, and STRO- 1 could be detected in all isolates (Fig. 1b). Optimizing cell culture, an optimal cell growth and maintenance was achieved using a plating density of $1 \times 10^{4}$ cells per $\mathrm{cm}^{2}$. During further passages, a daily doubling index of 2.02 was determined (Fig. 1c). The cells did not differentiate spontaneously during culture expansion into any morphologically identifiable cell type.

Immunophenotypic characterization of stem/progenitor cells isolated from tracheotomy

To characterize the isolated stem/progenitor cell population, $\mathrm{CD}$ surface antigen marker expression was analyzed by means of flow cytometric measurement (Fig. 2). The isolated cells showed a distinct phenotypic population ( $>90 \%$ homogeneous in passage 4 ). The stem/progenitor cell isolates were negative for CD45 (leukocyte common antigen) and CD34 (gp105-120), indicating that they were not of hematopoietic origin. The cells expressed CD29 (b1 integrin), CD54 (intercellular adhesion molecule-1) and $\mathrm{CD} 140 \mathrm{~b}$ ( $b$ platelet-derived growth factor receptor). Analysis for the hyaluronate receptor (CD44), ecto-5'-nucleotidase 

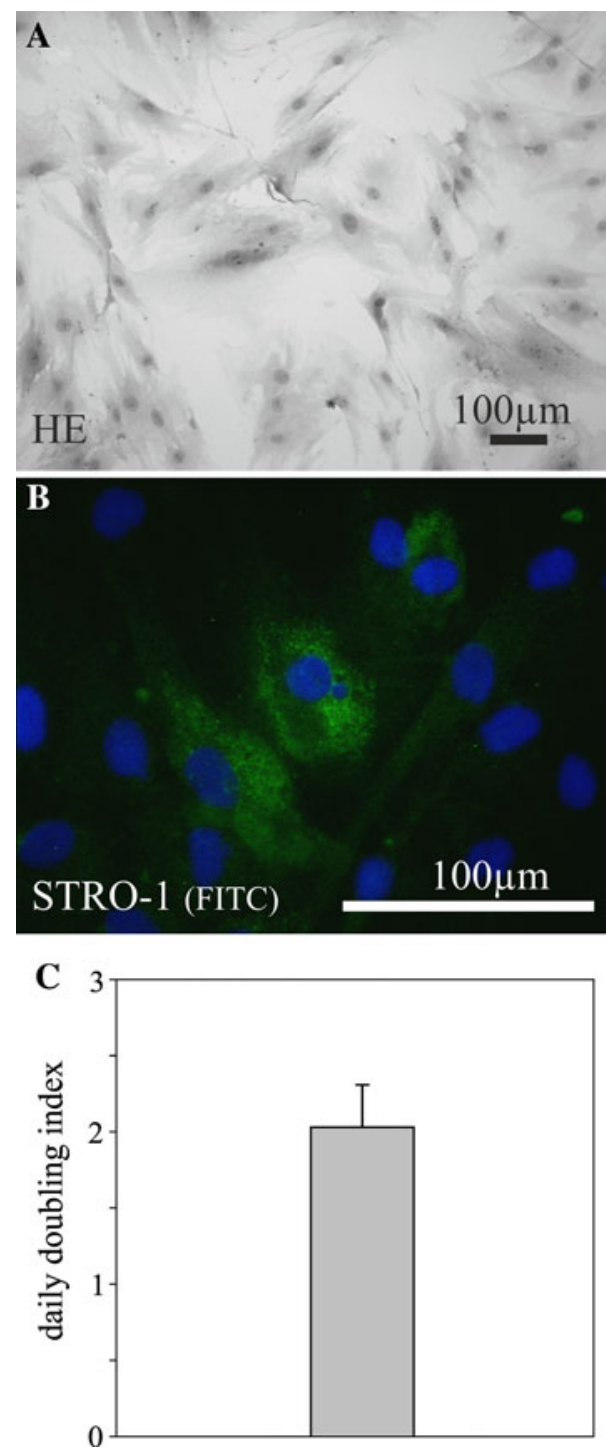

Fig. 1 Hematoxylin-eosin (HE) staining of proliferating adipose tissue-derived cells from the neck (passage 4) isolated by plastic adherence after tracheotomy demonstrates a spindle-shaped morphology (a). The cells stained positive for STRO-1 (b) and showed a stable daily doubling index of 2.02 during further passages (c). Nuclei are stained blue using DAPI

(CD73) and CD90 (thymocyte differentiation antigen-1, Thy-1) revealed strong expression. The matrix receptor CD105 (endoglin, SH2), the adhesion molecule CD166 (activated leukocyte cell adhesion molecule) and CD13 (aminopeptidase-N) were found to be expressed. The cells did not display an expression of CD106 (vascular cell adhesion molecule-1).

Multilineage differentiation of tracheotomy-derived stem/progenitor cells

During multilineage differentiation and characterization of adipose tissue-derived cell cultures, the isolates were regularly analyzed by histochemical and immunofluorescence staining for adipogenic, osteogenic and chondrogenic cell types. RT-PCR analysis confirmed the multilineage differentiation of the isolated human stem/progenitor cells. We found that the amount of differentiated cells increased up to almost $70-90 \%$ after 25 days of cultivation in lineage-specific induction medium.

\section{Adipogenic differentiation}

To analyze the adipogenic differentiation, the stem/progenitor cells were induced in the expanded monolayer cultures by treatment with IBMX, dexamethasone, insulin and indomethacin. Morphologic changes as well as the formation of neutral lipid vacuoles were apparent as early as 1 week after induction and visualized by staining with Sudan III (Fig. 3a). Sudan III positivity was only observed after application of adipogenic medium. Initially, no staining was detectable in the stem/progenitor cell cultures. After 25 days of adipogenic induction, almost $70 \%$ of all cells were positive for the lipid staining and eventually filled with lipid vacuoles (Fig. 3a; 0 day vs. 25 days: $p \leq 0.001$ ).

After 1 week, adipogenic induction of tracheotomyderived stem/progenitor cells resulted in lineage-specific gene expression and increase of marker molecules such as the nuclear receptor peroxisome proliferation-activated receptor $\gamma(P P A R \gamma)$, the fatty acid-binding protein $(F A B P)$ $a P 2$ and the CCAAT enhancer-binding protein alpha $(C /$ EBPalpha)-molecules controlling adipocyte differentiation and function (Fig. 3b; 0 day vs. 25 days: $p \leq 0.05$ ).

\section{Osteogenic differentiation}

To assess the osteogenic differentiation, the stem/progenitor cells were induced by dexamethasone, glycerol phosphate and ascorbic acid in the presence of $10 \%$ FCS. As early as 1 week after induction, aggregates of cells showed expression of alkaline phosphatase (AP) which increased during the ongoing differentiation, resulting in almost $100 \%$ APpositive cells on day 25 (Fig. $4 \mathrm{~b} ; 0$ day vs. 25 days: $p \leq 0.001$ ). Immunostaining revealed the expression of the osteogenic marker molecules osteopontin and bone sialoprotein (Fig. 4b). Both molecules could be detected after 9 days of osteogenic differentiation and the number of positive cells increased during further cultivation, indicating osteogenic differentiation. Before application of the osteogenic medium, no protein expression of bone sialoprotein was observed in the undifferentiated cell cultures by immunostaining, whereas a basal expression of osteopontin could be detected (data not shown).

These results were confirmed at the gene expression level by RT-PCR analysis (Fig. 4c). Osteopontin was already expressed in undifferentiated cell cultures, as it has 
Fig. 2 A representative flow cytometric analysis of adipose tissue-derived cells from the neck at the 4 th passage is shown. Isotype-matched human antibody control staining is depicted in white. The specific markers are shown in gray
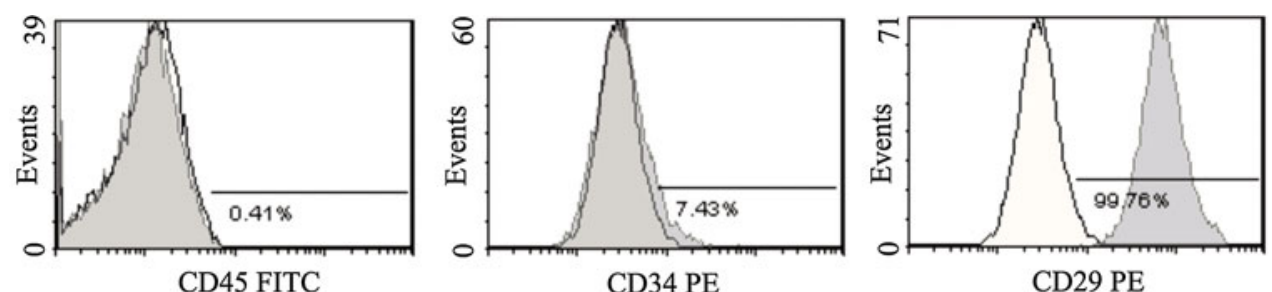

CD29 PE

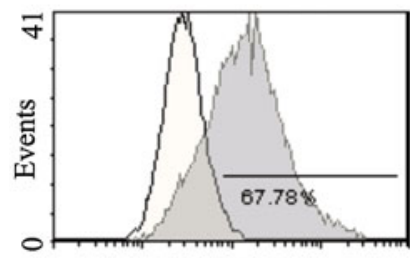

CD54 PE
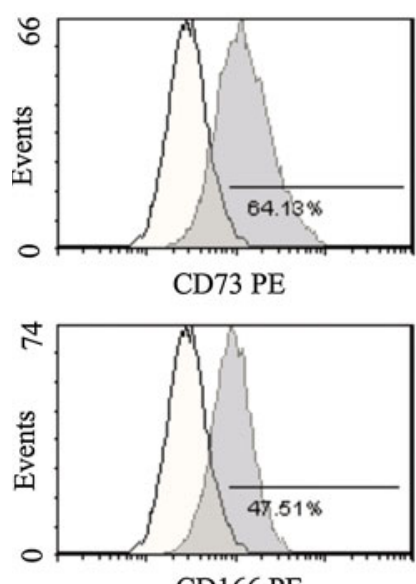

CD166 PE

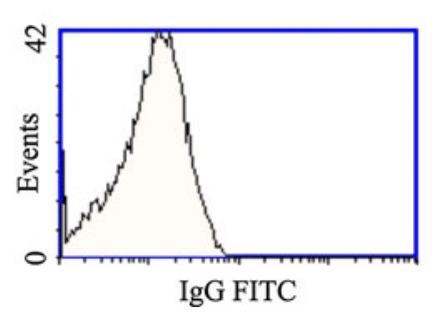

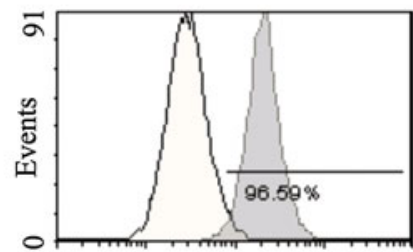

CD140b PE

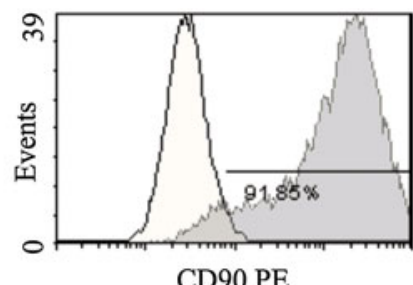

CD90 PE

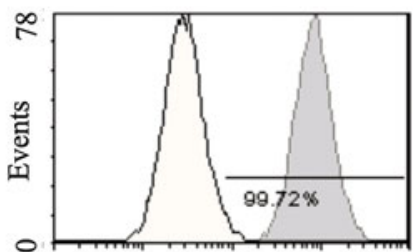

CD44 PE

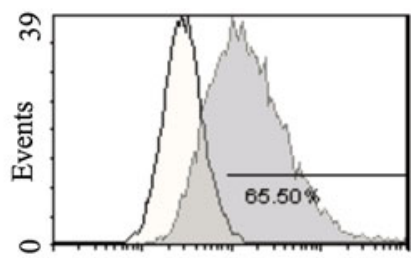

CD105 PE

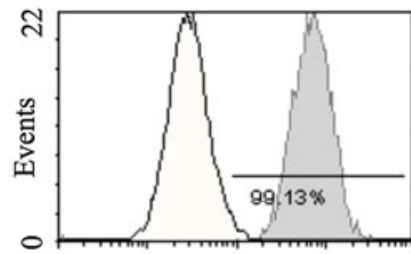

CD13 PE

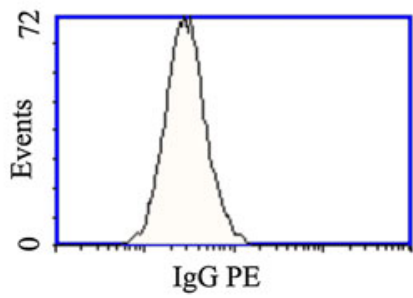

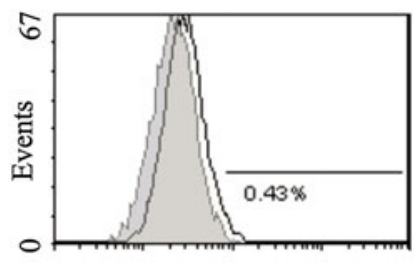

CD106 PE

for Alcian blue after 18 days of cultivation demonstrating a proteoglycan-rich extracellular matrix. Immunostaining revealed the expression of collagen type II, the major component of hyaline cartilage (Fig. 5b). Collagen Type X, which is expressed by hypertrophic chondrocytes, was detected at the end of the 25-day differentiation period. Before application of chondrogenic medium, no protein expression of the analyzed chondrogenic marker molecules could be found in the undifferentiated cell cultures by immunostaining (data not shown).

RT-PCR analysis confirmed chondrogenic differentiation and expression of collagen type II and demonstrated the expression of aggrecan, the major proteoglycan of cartilage tissue (Fig. 5c). Taken together, these results demonstrate that all analyzed tracheotomy-derived stem/progenitor cells were able to differentiate along the chondrogenic lineage. 
Fig. 3 Adipogenic differentiation of human adipose-tissue derived stem/progenitor cells from the neck during monolayer cultivation. Sudan III staining demonstrates adipogenic differentiation with a maximum on day 25 after induction of differentiation (a). Analysis of relative marker gene expression confirmed adipogenic differentiation of the stem/progenitor cells (b). Mean values \pm SEM derived from three independent experiments $(n=3)$ are shown. Bar $=100 \mu \mathrm{m} . * p \leq 0.05$, $* * * p \leq 0.001$
A
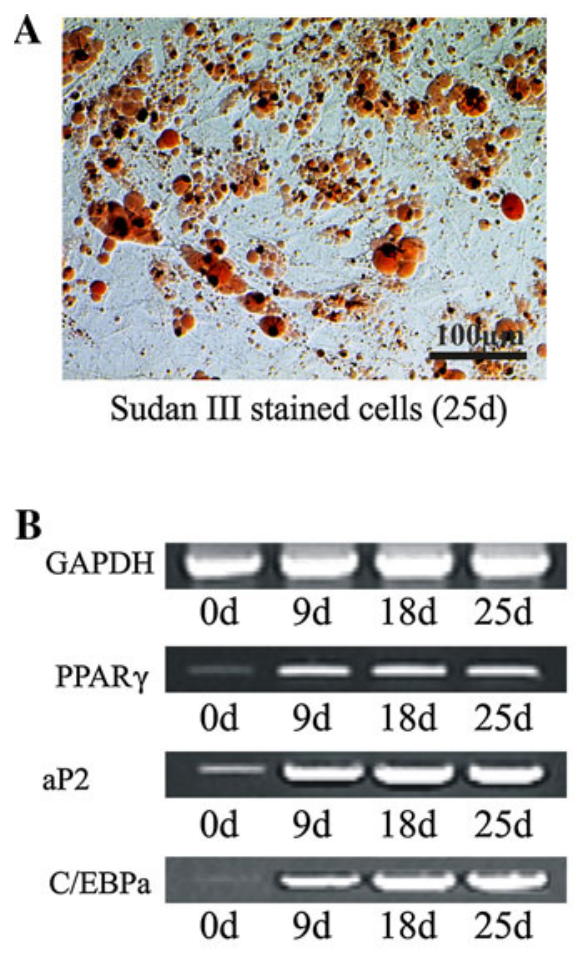
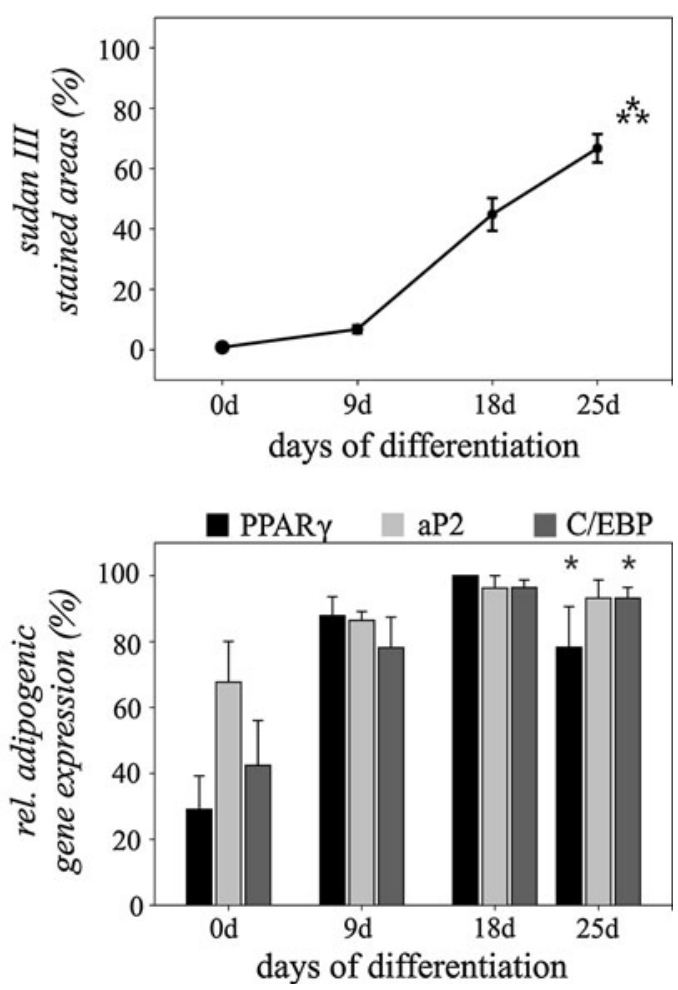

\section{Discussion}

Cells used in tissue engineering can be derived from numerous sources, including primary tissues, cell lines and stem cells. Stem/progenitor cells contribute to the homeostasis and regeneration of tissue after trauma and disease [23, 24]. Many sources of adult stem cells have been characterized, posting the hypothesis that stem cells capable of multilineage differentiation might reside in any post natalorgan [12]. Among them, bone marrow MSC have been found to differentiate along multiple mesenchymal lineages [9-11] and have currently been used for the clinical transplantation of a tissue-engineered airway [8, 25]. However, it is necessary to obtain these cells by general anesthetic procedures, bone marrow biopsies or even operations. These methods may complicate the routine clinical scenario.

Ideally, cells used for clinical transplantation should be (1) easy to harvest, (2) highly proliferative, (3) autologous and non-immunogenic and (4) able to differentiate into a variety of cell types with specialized functions [26]. Most patients undergoing extensive airway or head and neck surgery require open tracheotomy to secure airway passage until recovery of swallowing and respiratory function is reached. In this study we investigated if stem/progenitor cells applicable for tissue engineering of the airway function could be easily isolated from adipose tissue of the neck during an open tracheotomy.
Characteristics that define mesenchymal stem/progenitor cells include high proliferative potential, ability to generate primary colony-forming unit-fibroblast and the ability to differentiate into bone, fat and cartilage. The multilineage potential of adult stem cells, however, has often been considered an attribute of heterogenic cell isolates [27, 28]. Therefore, minimal criteria have been denominated to define human MSC [11]. First, the cells are plastic adherent and second, they express the CD marker molecules CD105 (endoglin), CD73 (5'-nucleotidase) as well as CD90 (Thy1) and do not express the leukocyte marker molecule CD45 and the marker molecule CD34 for primitive hematopoietic progenitor cells. However, current studies demonstrated that MSC cannot be distinguished from fibroblasts by flow cytometric analysis using a panel of common marker molecules [29]. Furthermore, various markers that are used to purify MSC from marrow aspirates are rapidly down regulated following ex vivo expansion [30] or have been attributed to different subpopulations [31]. Therefore, the third criterion plays a pivotal role: MSC must show the multilineage capacity to differentiate into adipogenic, osteogenic and chondrogenic cells.

In this study we were able to demonstrate that proliferating cells could be easily isolated from adipose tissue surrounding the trachea by adherence to plastic culture dishes. The isolated cells showed a spindle-shaped morphology and expressed $\mathrm{CD}$ marker molecules characteristic for MSC [11, 30] and adipose tissue-derived stem cells [32]. 
Fig. 4 Osteogenic differentiation of human adipose-tissue derived stem/progenitor cells from the neck during monolayer cultivation. Alkaline phosphatase (AP) staining demonstrates osteogenic differentiation with a maximum on day 25 after induction of differentiation $(\mathbf{a})$

Expression of osteopontin (OP) and bone sialoprotein (BSP) is shown by immunostaining. Nuclei are stained blue using DAPI (b). Analysis of relative marker gene expression confirmed osteogenic differentiation of the stem/progenitor cells (c). Mean values \pm SEM derived from three independent experiments $(n=3)$ are shown. Bar $=100 \mu \mathrm{m} . * * * p \leq 0.001$

\section{A}

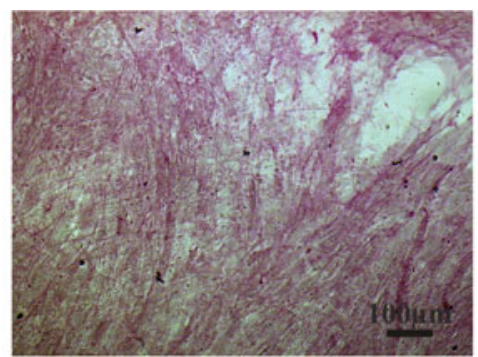

Alkaline phosphatase stained cells (25d)

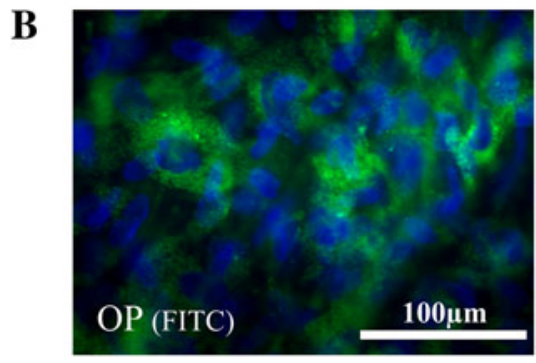

C

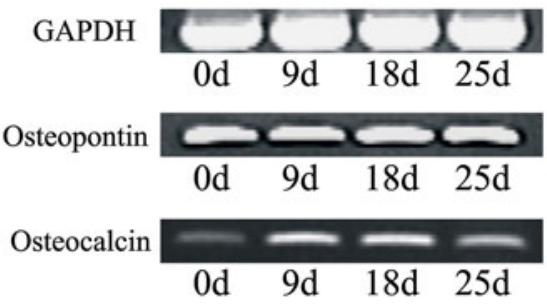

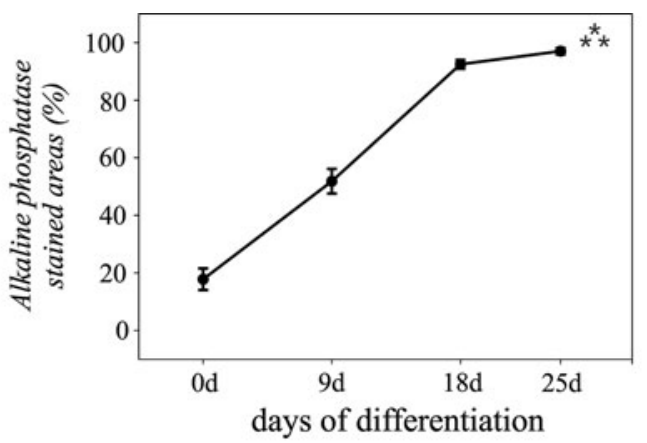
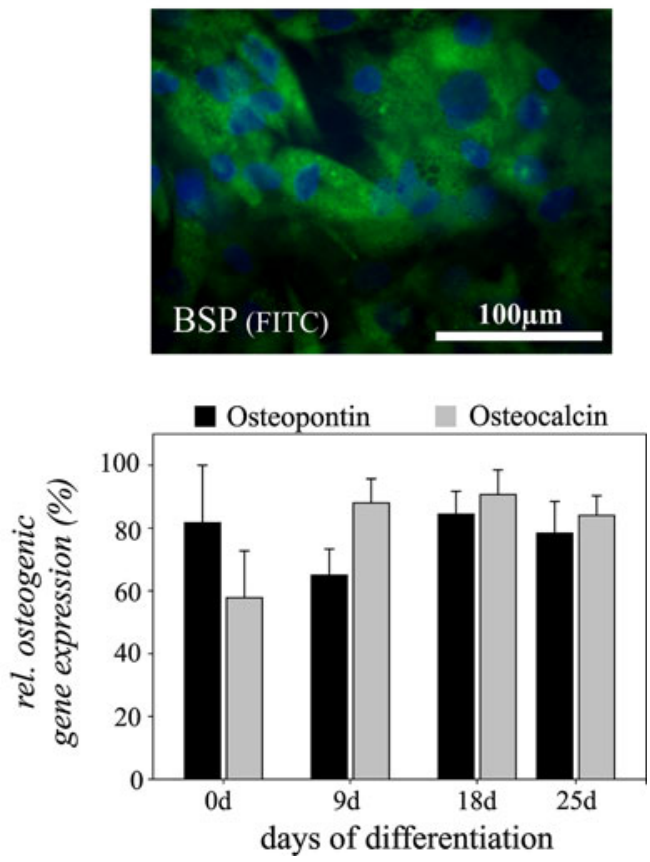

Moreover, these cells were capable of differentiating efficiently into adipogenic, osteogenic and chondrogenic cell types under specific culture conditions in vitro. In addition, it has been shown that multipotential adipose tissuederived stem cells accelerated neovascularization and epithelialization in an animal model of a tissue-engineered trachea [13]. Recently, there has also been evidence that fibroblasts, closely related to MSC populations [33, 34] enhanced epithelial differentiation and proliferation in an applied tracheal prosthesis [35].

\section{Conclusion}

This study was able to verify the hypothesis that stem/progenitor cells can be easily isolated from adipose tissue of the neck during tracheotomy. The stem/progenitor cell isolates showed characteristics of multipotent adult stem cells, similar to those of bone marrow-derived MSC, and given the appropriate culture conditions demonstrated multilineage differentiation into adipogenic, osteogenic and chondrogenic cells. Furthermore, there is strong evidence that these adipose tissue-derived stem cells from the neck meet the requirements for MSC [11]. Thus, additional operative interventions to obtain bone marrow MSC through multiple time-intensive general anesthetic procedures, biopsies and operations may no longer be necessary to receive MSC-derived tissue-engineered airway transplantation. Direct sources of autologous, highly proliferative, multipotent stem cells for clinical transplantation which can be safely extracted during a one-time procedure will be pivotal for regenerative medicine in the future. To safely apply stem/progenitor cells in future medicine it will also be necessary to understand the integration and interaction of these cells with surrounding cellular structures [36]. The goal of future studies is to optimize the differentiation and application of adipose tissue-derived stem/ progenitor cells from the neck for the reconstructive surgery of tracheal or bronchial airway. 
Fig. 5 Chondrogenic differentiation of human adipose tissuederived stem/progenitor cells from the neck. Alcian blue staining of cryosectioned "micromass bodies" (MMB) demonstrates chondrogenic differentiation with a maximum on day 25 after induction of differentiation (a). Expression of collagen type II and $\mathrm{X}$ is demonstrated by immunostaining. Nuclei are stained blue using DAPI (b). Analysis of relative marker gene expression confirmed chondrogenic differentiation of the stem/progenitor cells (c). Mean values \pm SEM derived from three independent experiments $(n=3)$ are shown. Bar $=100 \mu \mathrm{m}$. ***p $\leq 0.001$
A

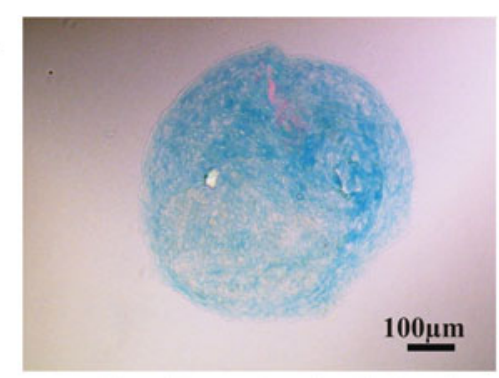

Alcian blue stained cells (25d)

B

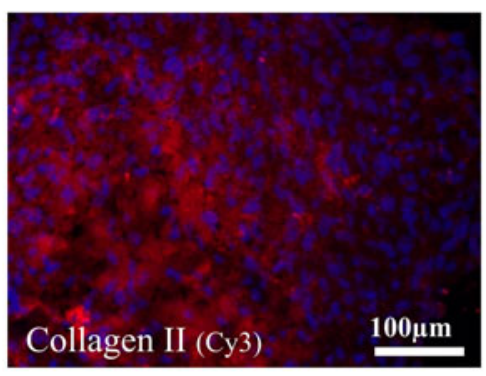

C

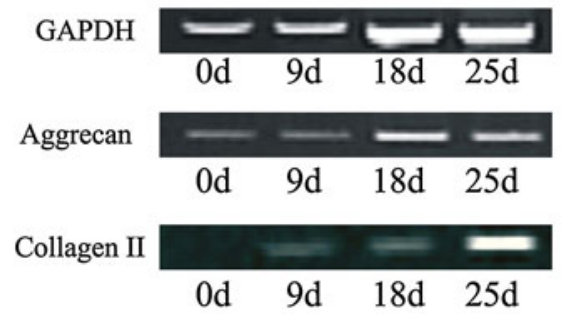

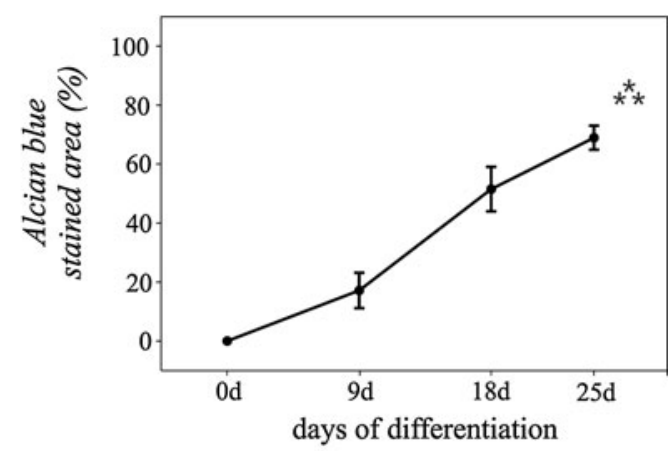
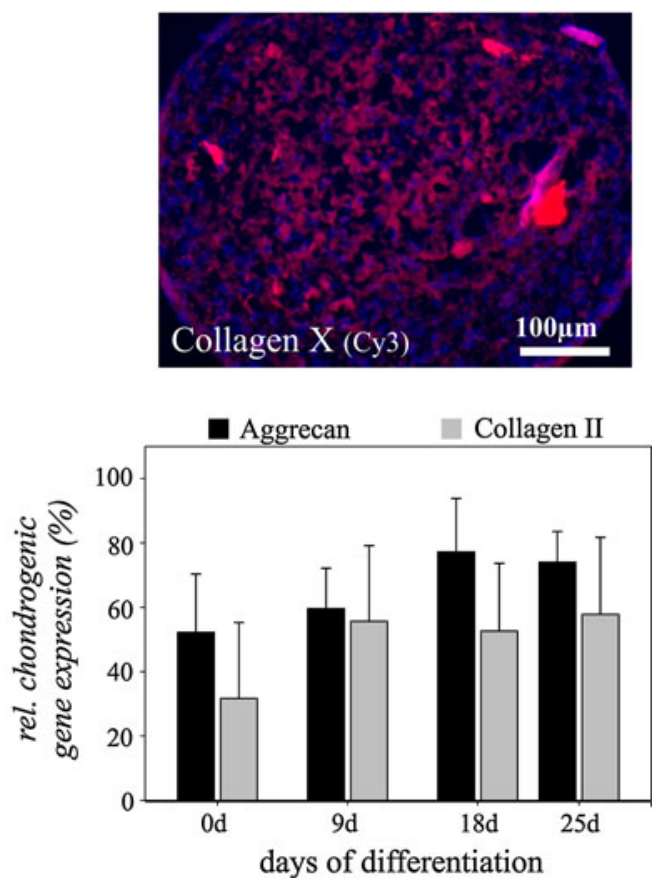

Ethical conduct of research The authors state that they have obtained appropriate institutional review board approval or have followed the principles outlined in the Declaration of Helsinki for all human experimental investigations. In addition, for investigations involving human subjects, informed consent has been obtained from the participants involved.

Acknowledgments The work was supported by the Medical Faculty of the University of Lübeck (Program Regenerative Medicine and the Junior Research Cluster: Epithelial inflammation, Lübeck, Germany) and Intermed Service GmbH \& Co. KG (Geesthacht, Germany). We are grateful to Barbara Andresen and Alexandra Tiedtke for their technical assistance.

Conflict of interest The work was supported by the Medical Faculty of the University of Lübeck (Program Regenerative Medicine and the Junior Research Cluster: Epithelial inflammation, Lübeck, Germany) and Intermed Service GmbH \& Co. KG (Geesthacht, Germany). The authors have no further interest in companies or other entities that have an interest in the information in the contribution. There is no conflict of interest pending. The authors have no other relevant affiliations or financial involvement with any organization or entity with a financial interest in or financial conflict with the subject matter or materials discussed in the manuscript apart from those disclosed.

Open Access This article is distributed under the terms of the Creative Commons Attribution License which permits any use, distribution, and reproduction in any medium, provided the original author(s) and the source are credited.

\section{References}

1. Kato R, Kakizaki T, Hangai N, Sawafuji M, Yamamoto T, Kobayashi T, Watanabe M, Nakayama M, Kawamura M, Kikuchi K et al (1993) Bronchoplastic procedures for tuberculous bronchial stenosis. J Thorac Cardiovasc Surg 106(6):1118-1121

2. Iwamoto Y, Miyazawa T, Kurimoto N, Miyazu Y, Ishida A, Matsuo K, Watanabe Y (2004) Interventional bronchoscopy in the management of airway stenosis due to tracheobronchial tuberculosis. Chest 126(4):1344-1352. doi:10.1378/chest.126. 4.1344

3. Omori K, Nakamura T, Kanemaru S, Asato R, Yamashita M, Tanaka S, Magrufov A, Ito J, Shimizu Y (2005) Regenerative medi- 
cine of the trachea: the first human case. Ann Otol Rhinol Laryngol 114(6):429-433

4. Naito H, Tojo T, Kimura M, Dohi Y, Zimmermann WH, Eschenhagen T, Taniguchi $S$ (2011) Engineering bioartificial tracheal tissue using hybrid fibroblast-mesenchymal stem cell cultures in collagen hydrogels. Interact Cardiovasc Thorac Surg 12(2):156161. doi:10.1510/icvts.2010.253559

5. Grillo HC (2003) Tracheal replacement. J Thorac Cardiovasc Surg 125(4):975. doi: $10.1067 / \mathrm{mtc} .2003 .260$

6. Sato T, Tao H, Araki M, Ueda H, Omori K, Nakamura T (2008) Replacement of the left main bronchus with a tissue-engineered prosthesis in a canine model. Ann Thorac Surg 86(2):422-428. doi:10.1016/j.athoracsur.2008.04.015

7. Martinod E, Seguin A, Holder-Espinasse M, Kambouchner M, Duterque-Coquillaud M, Azorin JF, Carpentier AF (2005) Tracheal regeneration following tracheal replacement with an allogenic aorta. Ann Thorac Surg 79 (3):942-948. (discussion 949). doi:10.1016/j.athoracsur.2004.08.035

8. Macchiarini P, Jungebluth P, Go T, Asnaghi MA, Rees LE, Cogan TA, Dodson A, Martorell J, Bellini S, Parnigotto PP, Dickinson SC, Hollander AP, Mantero S, Conconi MT, Birchall MA (2008) Clinical transplantation of a tissue-engineered airway. Lancet 372(9655):2023-2030. doi:10.1016/S0140-6736(08)61598-6

9. Pittenger MF, Mackay AM, Beck SC, Jaiswal RK, Douglas R, Mosca JD, Moorman MA, Simonetti DW, Craig S, Marshak DR (1999) Multilineage potential of adult human mesenchymal stem cells. Science 284(5411):143-147

10. Kramer J, Bohrnsen F, Lindner U, Behrens P, Schlenke P, Rohwedel $\mathrm{J}$ (2006) In vivo matrix-guided human mesenchymal stem cells. Cell Mol Life Sci 63(5):616-626. doi:10.1007/s00018-005-5527-z

11. Dominici M, Le Blanc K, Mueller I, Slaper-Cortenbach I, Marini F, Krause D, Deans R, Keating A, Prockop D, Horwitz E (2006) Minimal criteria for defining multipotent mesenchymal stromal cells. The International Society for Cellular Therapy position statement. Cytotherapy 8(4):315-317. doi:10.1080/14653240600 855905

12. da Silva MeirellesL, Chagastelles PC, Nardi NB (2006) Mesenchymal stem cells reside in virtually all post-natal organs and tissues. J Cell Sci 119(Pt 11):2204-2213. doi:10.1242/jcs.02932

13. Suzuki T, Kobayashi K, Tada Y, Suzuki Y, Wada I, Nakamura T, Omori K (2008) Regeneration of the trachea using a bioengineered scaffold with adipose-derived stem cells. Ann Otol Rhinol Laryngol 117(6):453-463

14. Johnstone B, Hering TM, Caplan AI, Goldberg VM, Yoo JU (1998) In vitro chondrogenesis of bone marrow-derived mesenchymal progenitor cells. Exp Cell Res 238(1):265-272. doi:10.1006/ excr.1997.3858

15. Bohrnsen F, Lindner U, Meier M, Gadallah A, Schlenke P, Lehnert H, Rohwedel J, Kramer J (2009) Murine mesenchymal progenitor cells from different tissues differentiated via mesenchymal microspheres into the mesodermal direction. BMC Cell Biol 10:92. doi:10.1186/1471-2121-10-92

16. Dennis JE, Carbillet JP, Caplan AI, Charbord P (2002) The STRO$1+$ marrow cell population is multipotential. Cells Tissues Organs $170(2-3): 73-82$

17. Linsenmayer TF, Hendrix MJ (1980) Monoclonal antibodies to connective tissue macromolecules: type II collagen. Biochem Biophys Res Commun 92(2):440-446

18. Schmid TM, Linsenmayer TF (1985) Immunohistochemical localization of short chain cartilage collagen (type $\mathrm{X}$ ) in avian tissues. J Cell Biol 100(2):598-605

19. Dorheim MA, Sullivan M, Dandapani V, Wu X, Hudson J, Segarini PR, Rosen DM, Aulthouse AL, Gimble JM (1993) Osteoblastic gene expression during adipogenesis in hematopoietic supporting murine bone marrow stromal cells. J Cell Physiol 154(2):317-328. doi:10.1002/jcp.1041540215
20. Rodriguez AM, Elabd C, Delteil F, Astier J, Vernochet C, SaintMarc P, Guesnet J, Guezennec A, Amri EZ, Dani C, Ailhaud G (2004) Adipocyte differentiation of multipotent cells established from human adipose tissue. Biochem Biophys Res Commun 315(2):255-263. doi:10.1016/j.bbrc.2004.01.053

21. Lin Y, Luo E, Chen X, Liu L, Qiao J, Yan Z, Li Z, Tang W, Zheng $X$, Tian W (2005) Molecular and cellular characterization during chondrogenic differentiation of adipose tissue-derived stromal cells in vitro and cartilage formation in vivo. J Cell Mol Med 9(4):929-939

22. Kramer PR, Nares S, Kramer SF, Grogan D, Kaiser M (2004) Mesenchymal stem cells acquire characteristics of cells in the periodontal ligament in vitro. J Dent Res 83(1):27-34

23. Valtieri M, Sorrentino A (2008) The mesenchymal stromal cell contribution to homeostasis. J Cell Physiol 217(2):296-300. doi:10.1002/jcp. 21521

24. Hilfiker A, Kasper C, Hass R, Haverich A (2011) Mesenchymal stem cells and progenitor cells in connective tissue engineering and regenerative medicine: is there a future for transplantation? Langenbecks Arch Surg 396(4):489-497. doi:10.1007/s00423-011-0762-2

25. Hanson S, Thibeault SL, Hematti P (2010) Clinical applications of mesenchymal stem cells in laryngotracheal reconstruction. Curr Stem Cell Res Ther 5(3):268-272

26. Vacanti JP, Langer R, Upton J, Marler JJ (1998) Transplantation of cells in matrices for tissue regeneration. Adv Drug Deliv Rev 33(1-2):165-182

27. Kuznetsov SA, Krebsbach PH, Satomura K, Kerr J, Riminucci M, Benayahu D, Robey PG (1997) Single-colony derived strains of human marrow stromal fibroblasts form bone after transplantation in vivo. J Bone Miner Res 12(9):1335-1347. doi:10.1359/jbmr.1997. 12.9.1335

28. Phinney DG, Kopen G, Righter W, Webster S, Tremain N, Prockop DJ (1999) Donor variation in the growth properties and osteogenic potential of human marrow stromal cells. J Cell Biochem 75(3):424-436

29. Wagner W, Ho AD (2007) Mesenchymal stem cell preparationscomparing apples and oranges. Stem Cell Rev 3(4):239-248. doi:10.1007/s12015-007-9001-1

30. Gronthos S, Zannettino AC, Hay SJ, Shi S, Graves SE, Kortesidis A, Simmons PJ (2003) Molecular and cellular characterisation of highly purified stromal stem cells derived from human bone marrow. J Cell Sci 116(Pt 9):1827-1835

31. Zimmerlin L, Donnenberg VS, Pfeifer ME, Meyer EM, Peault B, Rubin JP, Donnenberg AD (2010) Stromal vascular progenitors in adult human adipose tissue. Cytometry A 77(1):22-30. doi:10.1002/cyto.a.20813

32. Tapp H, Hanley EN Jr, Patt JC, Gruber HE (2009) Adipose-derived stem cells: characterization and current application in orthopaedic tissue repair. Exp Biol Med (Maywood) 234(1):1-9. doi:10.3181/0805/MR-170

33. Haniffa MA, Collin MP, Buckley CD, Dazzi F (2009) Mesenchymal stem cells: the fibroblasts' new clothes? Haematologica 94(2):258-263. doi:10.3324/haematol.13699

34. Alt E, Yan Y, Gehmert S, Song YH, Altman A, Vykoukal D, Bai X (2011) Fibroblasts share mesenchymal phenotypes with stem cells, but lack their differentiation and colony-forming potential. Biol Cell 103(4):197-208. doi:10.1042/BC20100117

35. Nomoto Y, Kobayashi K, Tada Y, Wada I, Nakamura T, Omori K (2008) Effect of fibroblasts on epithelial regeneration on the surface of a bioengineered trachea. Ann Otol Rhinol Laryngol 117(1):59-64

36. Tsigkou O, Pomerantseva I, Spencer JA, Redondo PA, Hart AR, O'Doherty E, Lin Y, Friedrich CC, Daheron L, Lin CP, Sundback CA, Vacanti JP, Neville C (2010) Engineered vascularized bone grafts. Proc Natl Acad Sci USA 107(8):3311-3316. doi:10.1073/ pnas.0905445107 